\title{
A NOTAÇÃO MUSICAL E A RELAÇÃO CONSCIENTE COM A MÚSICA: ELEMENTOS PARA REFLETIR SOBRE A IMPORTÂNCIA DA NOTAÇÃO COMO CONTEÚDO ESCOLAR
}

\author{
The musical notation and conscious \\ relationship with music: elements to reflect \\ on the importance of notation as school \\ subject
}

\author{
La notación musical y la relación consciente \\ con la música: elementos para reflexionar \\ acerca de la importancia de la notación \\ como contenido escolar
}

\author{
Thiago Xavier De Abreu \\ Universidade Estadual de Ponta Grossa \\ parathiagoxavier@gmail.com
}

NewTon Duarte

Universidade Estadual Paulista newton.duarte@unesp.br

\begin{abstract}
Resumo: O presente trabalho analisa o papel da notação como um conteúdo escolar da educação musical. Nosso objetivo é demonstrar que o aprendizado da escrita e da leitura da música supera a visão pragmática e utilitária da notação que reduz a aquisição desse conhecimento à capacidade de leitura da partitura. Trata-se de um salto qualitativo na consciência dos elementos musicais e, portanto, na relação do indivíduo com a música. Nossa abordagem parte da discussão da importância da notação para o desenvolvimento da música ocidental, observando-a como expressão objetiva do desenvolvimento da consciência do ser humano sobre a sua própria prática musical. A apropriação desse conteúdo reproduz, assim, esses traços na consciência do indivíduo, transformando sua relação com a música. Concluímos ressaltando a importância da notação para a formação musical e destacando a análise aqui apresentada como uma contribuição para a reflexão sobre a importância desse conteúdo para a educação musical.
\end{abstract}

Palavras-chave: Notação. Educação escolar. Pedagogia histórico-crítica.

Abstract: This paper analyzes the role of notation as a school content of music education. Our aim is to demonstrate that learning to write and read music goes beyond the pragmatic and utilitarian view of notation that reduces the acquisition of this knowledge to the ability of reading the score. Actually, it's a qualitative leap in the awareness of the musical elements and, therefore, in the relation of the individual to the music. Our approach starts from the discussion of the importance of notation for the development of Western music, observing it as an objective expression of the development of the human being's consciousness about his own musical practice. The appropriation of this content thus reproduces these traits in the individual's consciousness, transforming their relation to music. We conclude by highlighting the importance of notation for music education and accentuating the analysis presented here as a contribution to the reflection on the importance of this content for music education.

Keywords: Notation. School education. Historical critical pedagogy.

Resumen: Este artículo analiza el papel de la notación como contenido escolar de la educación musical. Nuestro objetivo es demostrar que aprender a escribir y leer música supera la visión pragmática y utilitaria de la notación, que reduce la adquisición de este conocimiento a la capacidad de leer la partitura. Esto corresponde a un salto cualitativo en la conciencia de los elementos musicales y, por lo tanto, en la relación del individuo con la música. Nuestro enfoque parte de la discusión sobre la importancia de la notación para el desarrollo de la música occidental, observándola como una expresión objetiva del desarrollo de la conciencia humana sobre su propia práctica musical. La apropiación de este contenido reproduce así estos rasgos en la conciencia del individuo, transformando su relación con la música. Concluimos señalando la importancia de la notación para la educación musical y destacando el análisis presentado aquí como una contribución a la reflexión sobre la importancia de este contenido para la educación musical.

Palabras clave: Notación. Educación escolar. Pedagogía histórico-crítica. 
Embora educadores musicais acreditem intuitivamente na importância da notação musical para a formação de um indivíduo, muitas vezes a resposta à pergunta “por que ensinar notação?” não ultrapassa esse âmbito da intuição, carecendo de profundidade e de elementos teóricos que forneçam fundamentos concretos para o entendimento do papel educacional desse conteúdo escolar. Talvez seja por isso que, principalmente no século XX, a aquisição da capacidade de escrita e leitura da música passe a ser questionada em seu valor educativo, chegando mesmo a ser considerada algo contraposto a uma prática musical rica.

A critica sustentada pelo pensamento educacional da música ao ensino da notação normalmente acusa o caráter mecânico dos processos de apropriação desse conteúdo, observando o conhecimento notacional simplesmente como um instrumental que nos proporciona executar ou compor uma obra, como apropriação de símbolos meramente abstratos que se limitam a orientar a prática musical. Tal abordagem mecânica é caracterizada como algo típico do chamado ensino conservatorial. Para Maura Penna (1995, p. 133-134), no ensino conservatorial ocorre

o tratamento dos mecanismos de representação gráfica como um código abstrato que se esgota em si mesmo, de modo que o referencial sonoro se perde. A partir dai, os princípios de organização formal (como as regras do tonalismo, o contraponto, harmonia, etc.) tornam-se um jogo de regras "matemáticas" que movimentam as notas no papel, e não o manejo consciente de relações sonoras.

Essa crítica à mecanicidade não se restringe à discussão sobre a notação musical, mas sim expressa transformações das concepções pedagógicas acerca dos processos de ensino e aprendizagem dos conteúdos técnicos e teóricos da música, abrangendo grande parte do pensamento educacional da música a partir do século XX. Para John Paynter (2002, p. 215, tradução nossa), por exemplo, seria necessária uma transformação nos currículos de educação musical, pois "um currículo torna-se muito facilmente um sumário do conhecimento a ser passado adiante, competências estabelecidas a serem adquiridas e fatos bem atestados a serem memorizados". Murray Schafer (1991, p. 285) parece concordar com o educador britânico, pois entende que o currículo tradicional não abarca a natureza "fundamentalmente expressiva" da música: "Ela é isso, deveria ser assim, porém, com a ênfase dada à teoria, à técnica e ao trabalho da memória, a música torna-se predominantemente uma ciência do tipo acumulação de conhecimento."

O entendimento da apropriação da notação musical no seu sentido unicamente técnico e utilitarista, como mera aquisição da capacidade de execução de uma partitura, é comumente acompanhado da perspectiva na qual seu processo de ensino é tido como uma transmissão mecânica desse conteúdo à mente do aluno. Na verdade, trata-se da mesma problemática, de um lado, observada do ponto de vista dos conteúdos escolares (no caso, a notação musical), e, de outro, do prisma dos seus processos de ensino. 
Uma vez que a notação musical é tomada como um conteúdo cuja função formativa se encerra na mera execução instrumental, seu ensino acaba por ser concebido como um movimento mecânico de depósito desse conteúdo na mente do aluno. Nas palavras de Schafer (1991, p. 286), "na educação, e considerando o aspecto da transmissão de conhecimentos, o professor tem todas as respostas, e os alunos, a cabeça vazia - pronta para assimilar informações".

Mas seria a notação musical algo morto, estático, como um mero instrumental que se reduz ao atendimento estéril e mecânico das necessidades imediatas da performance? Seria possivel um indivíduo se apropriar desse conteúdo sem que isso transforme a relação entre ele e a música para além da capacidade de execução de uma partitura? Duarte (2016, p. 59) discute a inconsistência dessa perspectiva sobre os conteúdos escolares e seus processos de ensino destacando a relação dialética entre suas várias dimensões:

O ensino dos conteúdos escolares em nada se assemelha, portanto, a um deslocamento mecânico de conhecimentos dos livros ou da mente do professor para a mente do aluno, como se esta fosse um recipiente com espaços vazios a serem preenchidos por conteúdos inertes. O ensino é transmissão de conhecimento, mas tal transmissão está longe de ser uma transferência mecânica, um mero deslocamento de uma posição (o livro, a mente do professor) para outra (a mente do aluno). O ensino é o encontro de várias formas de atividade humana: atividade de conhecimento do mundo sintetizada nos conteúdos escolares, a atividade de organização das condições necessárias ao trabalho educativo, a atividade de ensino pelo professor e a atividade de estudo pelos alunos.

A atividade de ensino é um processo vivo, isto é, multideterminado, e cujos elementos não são coisas estáticas, mas sim envolvem várias formas de atividade humana, desde aquelas incluidas no momento exato do processo educativo (atividade do professor e atividade do aluno) até aquelas atividades humanas acumuladas nos conteúdos escolares, as quais medeiam a relação entre professor e aluno.

Neste artigo defenderemos precisamente esse caráter vivo da notação musical como um conteúdo escolar. Pretendemos demonstrar que o aprendizado da notação não se reduz à mera capacidade de escrita e leitura, mas sim corresponde à apropriação dos elementos que estruturam a prática musical. Tal perspectiva pode fornecer subsídios históricos e concretos para refletirmos sobre a importância da notação musical como um conteúdo da aula de música, ou seja, sua contribuição para a formação musical de uma pessoa. 


\section{A NOTAÇÃO COMO UM CLÁSSICO DA EDUCAÇÃO MUSICAL: RELAÇÕES ENTRE A NOTAÇÃO E O DESENVOLVIMENTO HISTÓRICO DA MÚSICA E DOS SEUS PROCESSOS EDUCACIONAIS}

O valor de um conteúdo escolar para a formação de um indivíduo emana da importância desse conteúdo para o desenvolvimento do gênero humano ${ }^{1}$ como um todo. Isso porque o desenvolvimento individual não está separado do desenvolvimento da humanidade, sendo, simplesmente, a manifestação concreta e particular deste. Trata-se de observar o processo formativo como uma relação dialética entre indivíduo e humanidade, ou, como definiu Saviani (2008b, p. 13), "o trabalho educativo é o ato de produzir, direta e intencionalmente, em cada indivíduo singular, a humanidade que é produzida histórica e coletivamente pelo conjunto dos homens". Cabe, então, às formas sistematizadas de atividade educacional definir, em meio à múltipla variedade de produções humanas na história, os elementos necessários para a formação de uma pessoa. Sobre isso, Saviani (2008b, p. 13-14) completa:

Quanto ao primeiro aspecto (a identificação dos elementos cul-
turais que precisam ser assimilados), trata-se de distinguir
entre o essencial e o acidental, o principal e o secundário, o
fundamental e o acessório. Aqui me parece de grande impor-
tância, em pedagogia, a noção de "clássico". O clássico não se
confunde com o tradicional e também não se opõe, necessaria-
mente, ao moderno e muito menos ao atual. O clássico é aquilo
que se firmou como fundamental, como essencial. Pode, pois,
constituir-se num critério útil para a seleção de conteúdos do
trabalho pedagógico.

O clássico não é algo ultrapassado, que ficou para trás na história humana e cuja apreensão se limite à internalização de regras ou fatos deslocados da vida. Clássico é aquilo que se conservou vivo na história precisamente por ser sempre necessário, ou seja, algo que sempre se mantém atual, na medida em que se tornou parte constitutiva da prática social. Esse é o caso da notação musical. As atividades de escrita e leitura há muito tempo estão presentes na prática musical e, portanto, também nos processos de ensino e aprendizagem da música. O advento da notação não significa somente o surgimento da capacidade de registro dos elementos musicais, mas também altera as condições da própria produção musical, tornando-se um traço indelével dessa trajetória histórica.

\footnotetext{
1 Empregamos a categoria de gênero humano com o mesmo significado que ela tem na leitura lukacsiana da filosofia marxista e no livro A individualidade para si, de Duarte (2013). Trata-se da humanidade no seu todo, o que inclui o processo de desenvolvimento tanto da espécie Homo sapiens como o conjunto das produções humanas constitutivas da cultura material e simbólica. Isso significa que as características fundamentais do gênero humano não se limitam aos traços biológicos de nossa espécie, mas abarcam também a esfera da vida, qualitativamente diferente da natural, que se acumula nos produtos da atividade humana, os quais se interpõem nas relações entre os indivíduos. Em outras palavras, a categoria de gênero humano está diretamente ligada ao estudo da esfera propriamente social da vida.
} 
As primeiras formas de escrita da música remetem ao período entre os séculos VII e IX. São as chamadas neumas, sinais gráficos que denotam direcionamentos melódicos para o canto dos textos litúrgicos (Bent; Hughes; Provine; Rastall; Kilmer; Hiley; Szendrei; Payne; Bent; Chew, 2001). Para Treitler (1984), a origem da notação neumática está diretamente ligada à efervescência econômica e cultural que ocorreu no período carolíngio, o qual, através das leis capitulares e da consequente organização da educação monasterial, criou as bases para o avanço de uma cultura letrada da música. Tal atividade notacional corresponde a uma tentativa de sistematização da prática musical, ou seja, de alcançar uma clareza e organização dos princípios centrais dessa prática no intuito de dominá-la, tanto no âmbito da performance musical quanto nos seus processos de ensino e aprendizagem. Apesar da extrema variedade das primeiras formas de escrita musical, o autor destaca esse elemento em comum:

O surgimento praticamente simultâneo de notações de tipos e propósitos fundamentalmente díspares, no entanto, sugere uma ideia que conecta todas elas: que sua própria existência é um reflexo, no domínio da música, da nova orientação da cultura escrita. Escreveu-se diferentes tipos de música, para diferentes propósitos particulares, de maneiras que rapidamente se tornaram altamente diferenciadas. Mas escreveu-se. E fez-se isso no interesse de um ideal transcendente de clareza e normatividade (Treitler, 1984, p. 142, tradução nossa).

$\mathrm{Na}$ continuidade desse progressivo processo de sistematização destacam-se, em um periodo mais à frente, as inovações notacionais criadas pelo monge Guido de Arezzo (992-1050), as quais fomentaram uma prática diferenciada da música, muito mais clara acerca dos elementos musicais, e cujos desenvolvimentos no campo da escrita e da leitura da música são decisivos, a tal ponto que ainda se mantêm presentes. Para Van Waesberghe (1951, p. 16, tradução nossa),

Guido de Arezzo fez duas grandes contribuições para a pedagogia da música: ele introduziu uma nova notação e desenvolveu um método para aprender a ler a música escrita nesse roteiro. Esse duplo evento deixou sua marca no ensino da música e dividiu sua história em duas fases: o periodo antigo, o tempo das neumas, vagas, nebulosas, dificeis ou impossiveis de decifrar, e do ensino viva voce, isto é, com aluno repetindo o mestre; e o novo período, com uma notação clara, fácil de ler, juntamente com um novo método para aprender o cantus ignotus com uma visão de canto à prima vista. Ainda estamos na era de Guido, já que, além de pequenas variações na notação e didática, seu sistema foi mantido até os dias atuais.

Desse ponto de vista, podemos considerar que as inovações notacionais promovidas pelo monge de Arezzo são elementos clássicos da prática musical, na medida em que determinaram - e continuam determinando - a trajetória 
histórica da música. Essa importância está atrelada a um salto qualitativo na normatização dos elementos musicais, isto é, a um avanço decisivo na consciência e no domínio dos próprios elementos da música, notadamente, os princípios da afinação. Nesse duplo processo de desenvolvimento (da consciência dos aspectos estruturais da música e de sua expressão objetiva em uma escrita), novas condições são colocadas à prática musical, mudando "toda a relação entre escrita e música na maior parte da Europa em um espaço de tempo notavelmente curto, criando as precondições para desenvolvimentos da maior importância na música ocidental" (Bent; Hughes; Provine; Rastall; Kilmer; Hiley; Szendrei; Payne; Bent; Chew, 2001, tradução nossa).

É nesse sentido que a tradição da notação musical converge com o próprio processo de desenvolvimento da música, algo que não está separado dos seus processos educacionais. Grout e Palisca (1994, p. 96, grifo dos autores) caracterizam as mudanças ocorridas no século XI que vieram a transformar definitivamente a música ocidental:

Nesses anos tiveram início certas mudanças que, quando levadas às últimas consequências, viriam a conferir à música do Ocidente muitas de suas características fundamentais, esses traços que a distinguem de outras músicas do mundo. Tais mudanças podem ser resumidas como se segue.

1. A composição foi a pouco e pouco substituindo a improvisação enquanto forma de criação de peças musicais [...]; só a partir de então podemos dizer que as obras musicais passaram a "existir" na forma como hoje as concebemos, independentemente de cada execução.

2. Uma obra composta podia ser ensinada e transmitida oralmente e podia sofrer alterações neste processo de transmissão. Mas a invenção da notação musical tornou possível escrever a música de uma forma definitiva o que podia ser aprendida a partir do manuscrito [...].

3. A música começou a ser mais conscientemente estruturada e sujeita a certos princípios ordenadores [...].

4. A polifonia começou a substituir a monofonia. É certo que a polifonia enquanto tal não é exclusivamente ocidental, mas foi a nossa música que, mais do que qualquer outra, se especializou nessa técnica $[\ldots]$.

As diferentes dimensões desse momento de transformação da música e de suas formas educacionais não são coisas isoladas, mas sim distintas faces de um mesmo processo. A concepção de composição de uma obra se transforma a partir do advento da notação musical. Em um processo composicional selecionam-se os momentos mais essenciais de uma improvisação assistemática e parcialmente aleatória, praticamente limitada ao âmbito imediato de sua execução, sintetizando, assim, as suas principais expressões musicais. A perspectiva de uma obra composicional, que, de certa forma, sempre esteve presente na prática musical via tradição oral, altera-se qualitativamente com a difusão da atividade da escrita e leitura da música. A notação não somente 
modificou a prática musical centralizando-a na composição, performance e apreciação de uma obra musical, mas exatamente isso significa também um desenvolvimento de uma relação mais consciente com os principios ordenadores da música.

Isso se manifesta musicalmente por meio da técnica polifônica. Tomemos, por exemplo, a transição da música eclesiástica característica da Idade Média, o cantochão, até a chamada ars nova (aproximadamente séculos XIII a XV), periodo em que as primeiras formas de polifonia são exploradas (Bent; Hughes; Provine; Rastall; Kilmer; Hiley; Szendrei; Payne; Bent; Chew, 2001; Grout; Palisca, 1994). A escrita musical do cantochão era baseada em neumas. Se observarmos a notação neumática com nossos olhos hodiernos tenderemos a tomá-la como uma forma relativamente imprecisa de indicação dos parâmetros musicais. Contudo, uma análise dessa natureza seria a-histórica, desconsiderando que tal notação correspondia exatamente ao nivel de desenvolvimento musical e da consciência dos princípios organizadores da música à época. Ou seja, a notação neumática não significa uma incapacidade dos músicos e intelectuais da música do período medieval de construir uma escrita musical precisa, mas sim era a forma notacional daquela música, isto é, que expressava o nivel de desenvolvimento musical daquela época.

O que chamamos de nivel de desenvolvimento musical significa simplesmente os limites e características da consciência e domínio dos elementos propriamente musicais. Isso fica claro se comparamos a notação por neumas com as inovações notacionais e musicais do periodo da ars nova. Esse período é tão importante no estudo histórico da música justamente porque nele a consciência dos elementos musicais já estabelecidos é ampliada, criando novas formas de expressão musical que se tornaram fundamentais na música ocidental: os princípios da polifonia. Mas tudo isso está diretamente ligado ao surgimento do sistema mensural de notação, que sistematiza novas possibilidades rítmicas e cujos elementos essenciais ainda hoje permanecem como alicerce da notação moderna, direcionando nossa prática musical (Bent; Hughes; Provine; Rastall; Kilmer; Hiley; Szendrei; Payne; Bent; Chew, 2001; Grout; Palisca, 1994).

A escrita e a leitura da música representam, assim, exemplos de conteúdos escolares típicos da educação musical, pois, do ponto de vista do desenvolvimento histórico da música e do ser humano, elas são clássicos. Os reflexos do advento da notação permanecem permeando toda nossa prática musical, direta ou indiretamente, seja na música erudita ou na popular - pense-se, por exemplo, no surgimento do sistema tonal a partir da polifonia, e de como a tonalidade ainda hoje determina a lógica da maioria das práticas musicais no mundo ocidental. A notação modificou de tal maneira a prática social da música que os elementos desse salto qualitativo não mais deixaram de estar presentes na estrutura musical.

Observando desse prisma a notação musical perde qualquer aspecto morto, estático, adquirindo uma vivacidade de conteúdo que emana do próprio desenvolvimento humano sobre a música. Não mais se apresenta como 
algo meramente abstrato, mas sim concreto, ${ }^{2}$ na medida em que torna objetivos principios essenciais da produção musical: uma figura de ritmo não é somente um sinal gráfico, mas uma sintese simbólica de uma forma socialmente convencionada de organizar o tempo, um dos parâmetros da música; o posicionamento de uma nota no pentagrama também não é algo aleatório, e sim uma relação gráfica objetiva que expressa outro parâmetro da música, a altura das notas. Consequentemente, os processos de ensino e aprendizagem da escrita e leitura perdem também seu caráter mecânico, apontando para uma rica dialética entre o indivíduo e a humanidade por meio da música.

\section{A NOTAÇÃO MUSICAL E O SALTO QUALITATIVO NA RELAÇÃO ENTRE O INDIVÍDUO E A MÚSICA}

Tratar a notação musical como sintese da atividade humana sobre o som implica também reconhecer o caráter vivo do processo de apropriação dessa atividade acumulada. Se a escrita é uma expressão objetiva dos elementos estruturais da música, seu domínio significa a incorporação desses elementos à individualidade. Aquilo que é tomado pelo senso comum como letra morta ganha vida na consciência e na prática individual. Trata-se de compreender a formação musical mediada pela escrita da música muito além da visão pragmática da execução de uma partitura, observando-a como uma dialética viva entre o indivíduo e a riqueza acumulada nas objetivações humanas. Marx (2004, p. 110, grifo do autor) destaca esse processo de formação do indivíduo mediado pelas objetivações utilizando, inclusive, a música como um dos exemplos:

[É] apenas pela riqueza objetivamente desdobrada da essência humana que a riqueza da sensibilidade humana subjetiva, que um ouvido musical, um olho para a beleza da forma, em suma as fruições humanas todas se tornam os sentidos capazes, sentidos que se confirmam como forças essenciais humanas, em parte recém-cultivados em parte recém-engendrados. Pois não só os cinco sentidos, como também os assim chamados sentidos espirituais, os sentidos práticos (vontade, amor etc.), numa palavra o sentido humano, a humanidade dos sentidos, vem a ser primeiramente pela existência do seu objeto, pela natureza humanizada. A formação dos cinco sentidos é um trabalho de toda a história do mundo até aqui.

\footnotetext{
2 O significado do termo "concreto" no materialismo histórico-dialético, perspectiva filosófica que fundamenta a pedagogia histórico-crítica e que orienta o presente trabalho, possui algumas especificidades. Na teoria marxista a concretude da realidade é uma concepção calcada na categoria de totalidade, isto é, da unidade complexa do real, ou, nas palavras de Marx (2008, p. 258): "O concreto é concreto, porque é síntese de múltiplas determinações, isto é, unidade do diverso." Nesse sentido, a realidade concreta não se limita àquela em que vivemos imediatamente nossas vidas; ela é uma totalidade, uma síntese de inúmeras relações naturais e sociais decorridas de todo o processo histórico. Por outro lado, uma vez que se trata de uma perspectiva filosófica materialista, tais determinantes históricos não são coisas abstratas, mas encontram-se sintetizados no objeto real e concreto, daí a escolha deste termo para expressar essa totalidade.
} 
O ouvido musical não se restringe à aptidão biológica da audição; ele é uma construção social que remete à trajetória histórica da própria música. Não somente a música é um resultado do desenvolvimento do gênero humano, mas também a capacidade de vivenciá-la. $\mathrm{Na}$ verdade, mais preciso seria observar ambas essas dimensões como dois polos de um mesmo processo de desenvolvimento: de um lado, tomado do ponto de vista objetivo, isto é, da obra musical, de outro, subjetivo, da capacidade de apropriar-se da riqueza humana contida nessa obra. A experiência musical, tal qual a própria música, é uma construção histórica da atividade humana sobre a realidade. É por isso que Marx afirma acima que os sentidos humanos "vêm a ser primeiramente pela existência do seu objeto". O filósofo alemão nos mostra que a experiência subjetiva proporcionada por uma determinada música só pode existir por meio de uma atividade precedente de objetivação dessa afetividade em um objeto musical.

Essa relação dialética entre passado e presente, entre o morto e o vivo, ou, no caso deste trabalho, entre a atividade humana de dominio dos elementos estruturais da música acumulada na notação que guia determinada prática musical, representa um processo de formação musical. Aquilo que parece inerte e meramente abstrato na escrita da música - e, exatamente por isso, seu ensino tomado como algo mecânico - ganha vida por meio de um processo de incorporação, que reproduz a riqueza ali acumulada na prática do individuo. Fundamentando-se precisamente nos escritos de Marx, Duarte (2016, p. 52-54) explica esse movimento de apropriação, ressaltando também suas implicações para a educação escolar:

[...] a atividade humana como produto é imprescindivel à atividade humana como processo. Quando a escola é criticada por trabalhar com "produtos prontos e acabados", parece-me que há nessa crítica um equívoco fundamental, o de considerar que os produtos da atividade social humana possam existir como coisas totalmente inertes e desvinculadas da prática social [...]. O produto, como síntese do processo, carrega atividade objetivada. É trabalho morto, mas que volta à vida ao ser incorporado como meio de novas atividades. Entretanto, para que o trabalho morto volte à vida e seja incorporado a novas atividades, é preciso que as pessoas se apropriem da atividade objetivada no produto. Ocorre que, por vivermos na sociedade capitalista, estamos habituados a identificar o processo de apropriação com a posse imediata e com a forma capitalista de apropriação que é a propriedade privada [...].

A apropriação dos resultados das atividades humanas, para que eles se incorporem a novas atividades, não se reduz ao ato físico da posse (ato mecânico), da mesma forma que não se reduz à propriedade privada, que é a forma capitalista de apropriação. Trata-se de algo muito mais rico e complexo: a atividade humana que existe no objeto como propriedade em repouso, como latência, é trazida novamente à vida ao se incorporar à atividade dos indivíduos. 
A visão utilitarista do ensino da notação musical parte do princípio - o qual consideramos equivocado - de que esse conteúdo possa ser apropriado sem que aquilo altere as relações entre o aluno e a música. Porém, de certa forma, é compreensivel que ela seja vigente na educação musical, uma vez que no capitalismo a concepção de apropriação é normalmente entendida no sentido da posse individual. A formação subjetiva que ocorre por meio da apropriação da riqueza objetivada nos produtos da humanidade, como a música, é, contudo, muito mais profunda, superando a noção de posse, na medida em que se trata de uma incorporação, e os limites privados por significar uma relação dinâmica entre o indivíduo e o gênero humano.

Do ponto de vista do processo educacional pode-se considerar que se trata aqui do que Saviani (2008a, p. 57) chama de catarse, ou a "efetiva incorporação dos instrumentos culturais, transformados agora em elementos ativos de transformação social". A atividade acumulada objetivamente nos produtos da humanidade é transmutada em propriedades da atividade individual, em aspectos da prática desse indivíduo, em traços da sua individualidade. Essa perspectiva nos proporciona uma visão materialista, histórica e dialética da formação de uma pessoa, pois essa apropriação da riqueza humana não é algo metafísico, como um espírito que domina o aluno; trata-se simplesmente de uma questão prática: a incorporação existe como fenômeno concreto na medida em que nossa prática é transformada, ou, nas palavras de Marx (2004, p. 108, grifo do autor), "seu comportamento para com o objeto é o acionamento da efetividade humana [...]".

Quando nos relacionamos com a notação musical não estamos somente utilizando uma ferramenta para a execução de uma música, mas, precisamente nessa relação, acionamos o conteúdo humano ali contido, tornamos viva uma prática musical que decorre do processo de desenvolvimento da humanidade como um todo. Isso não exclui o possivel caráter mecânico no domínio e na utilização da notação musical. A capacidade de utilização da notação, seja numa performance, composição ou análise/apreciação musical, é algo que deve ser aprendido, o que comumente significa um processo mecânico de execução de exercícios de escrita e leitura. Porém, dialeticamente, é justamente a partir de automatização desses elementos que se pode ocorrer um salto qualitativo do individuo perante a música. Saviani (2008b, p. 20) analisa a questão da alfabetização considerando os processos mecânicos de aprendizagem da escrita e leitura e a consequente transformação nas relações entre uma pessoa e o conteúdo da linguagem:

Ora, esse fenômeno está presente também no processo de aprendizagem através do qual se dá a assimilação do saber sistematizado, como o ilustra, de modo eloquente, o exemplo da alfabetização. Também aqui é necessário dominar os mecanismos próprios da linguagem escrita. Também aqui é preciso fixar certos automatismos, incorporá-los, isto é, torná-los parte de nosso corpo, de nosso organismo, integrá-los em nosso próprio ser. Dominadas as formas básicas, a leitura e a escrita podem fluir com segurança e desenvoltura. À medida que se 
vai libertando dos aspectos mecânicos, o alfabetizando pode, progressivamente, ir concentrando cada vez mais sua atenção no conteúdo, isto é, no significado daquilo que é lido ou escrito. Note-se que libertar, aqui, não tem o sentido de se livrar, quer dizer, abandonar, deixar de lado os ditos aspectos mecânicos. A libertação só se dá porque tais aspectos foram apropriados, dominados e internalizados, passando em consequência a operar no interior de nossa própria estrutura orgânica. Poder-se-ia dizer que o que ocorre, nesse caso, é uma superação no sentido dialético da palavra. Os aspectos mecânicos foram negados por incorporação e não por exclusão. Foram superados porque negados enquanto elementos externos e afirmados como elementos internos.

Assim como na linguagem escrita, os aspectos mecânicos da aprendizagem da notação musical existem somente enquanto seus princípios são coisas externas ao individuo. Na medida em que deles o aluno se apropria sua mecanicidade é superada. Tal internalização e a consequente relação automática entre o individuo e a escrita da música permitem que ele se relacione não mais com a notação em si mesma, mas com o conteúdo musical nela contido. Por outro lado - e dialeticamente -, o aluno não deixará de se relacionar com a notação musical nesse processo. A internalização não significa o abandono da notação, mas sim sua superação como elemento externo da relação entre o indivíduo e o conteúdo musical, tornando-se um elemento interno, organicamente ligado aos dois polos dessa relação.

Ao ser internalizada, a notação musical torna-se parte do indivíduo, parte do seu ser. Daí que a utilização do termo "incorporar" não seja casual, pois se trata de uma atividade de apropriação de elementos externos ao indivíduo, de transformação do que é externo em algo interno, que se torna um traço de sua natureza, uma parte constitutiva do seu ser. Por isso, Saviani (2008b) observa esse fenômeno como a criação de uma segunda natureza, ou seja, um processo de apropriação que integra de tal forma a riqueza contida nas objetivações humanas ao indivíduo que ela não mais se desvincula dele. Tamanha é essa vinculação que muitas vezes acredita-se que esses traços incorporados sejam naturais, isto é, que surjam espontaneamente no indivíduo, esquecendo-se que são coisas socialmente construídas; nas palavras de Saviani (2008b, p. 20): “As coisas acontecem como se se tratasse de uma habilidade natural e espontânea. E no entanto trata-se de uma habilidade adquirida e, frise-se, não de modo espontâneo. A essa habilidade só se pode chegar por um processo deliberado e sistemático."

Essa espontaneidade no trato com a música que surge a partir da internalização da notação pode confundir análises da prática musical. Por exemplo, nos casos onde o intérprete ou aluno já decorou determinada música e não precisa mais de sua partitura. De fato, o abandono da partitura pode contribuir na performance musical, na medida em que o intérprete/aluno pode mobilizar sua atenção para outros aspectos da execução. Mas isso não nega o papel central da notação na riqueza de sua apresentação, pois foi somente 
por meio dela que o conteúdo musical pôde ser internalizado e dominado a ponto de superar completamente a dependência gráfica imediata. Ou seja, a partitura deixou de ser um elemento externo nas relações entre o individuo e a música, permeando-as internamente. Inversamente, uma performance musical mecânica, "presa" à partitura, na qual o intérprete/aluno executa uma música sem reproduzir necessariamente a riqueza de conteúdo musical ali contida, ocorre precisamente porque esse músico ainda não internalizou tal conteúdo, que se encontra sintetizado objetivamente nos elementos gráficos. Sua relação com o conteúdo ainda é relativamente distante, pois a notação ainda se encontra como um elemento exterior, ainda não completamente apropriado.

Outro dado que dificulta análises acerca do tema é que, de fato, não é absolutamente imprescindivel que uma pessoa tenha se apropriado da notação para que se relacione com o conteúdo musical. Alguém que não tenha o conhecimento da escrita e leitura da música pode perfeitamente ser atingido de maneira afetiva por uma sinfonia de Beethoven, assim como não são raros os casos de grandes músicos que não possuem o conhecimento da notação. Mas se partíssemos desses fenômenos para justificar a dispensabilidade da escrita e da leitura da música estaríamos realizando uma análise meramente imediata e individual, deslocada do sentido histórico da notação musical. A música, como algo que acompanha de diferentes maneiras cada passo da trajetória do ser humano, acumulou essa experiência em produtos transmitidos via oral pela prática musical cotidiana e, posteriormente, pela escrita, a qual retroagiu sobre a prática cotidiana transformando a estrutura da música (polifonia, tonalidade). Dessa forma, o acionamento do conteúdo humano sintetizado na notação musical pode acontecer de maneira mais direta, como na utilização da partitura, mas também de forma indireta, como quando uma pessoa executa uma música encaminhando a resolução de trítonos sem necessariamente saber os principios que guiam essa resolução - algo que ocorre na maioria da prática social da música.

Mas tal acionamento indireto tem seus limites, já que nele as relações entre o indivíduo e os elementos estruturais da música ocorrem de maneira relativamente inconsciente. Para o materialismo histórico-dialético, o inconsciente é simplesmente a não consciência da realidade objetiva, incluindo-se nela a própria prática social, tanto a individual quanto a coletiva. Como esclarece Lukács (1966, p. 95, tradução nossa), trata-se de um problema de conteúdo: "Se e em que medida o conteúdo da consciência [...] coincide com a realidade objetiva, e se e em que medida o objeto e o comportamento a respeito do objeto são reproduzidos adequadamente pela consciência." Nesse sentido, uma determinada prática musical pode ocorrer sem que seus elementos centrais sejam coisas conscientes para o individuo que a pratica. Já a mediação da notação musical obriga o indivíduo a se relacionar mais conscientemente com esses elementos, com os princípios estruturam a música. Vygotski (1993, p. 232, tradução nossa, grifo nosso) observa esse mesmo salto qualitativo comparando a aprendizagem da escrita com a linguagem oral: 
Os signos da linguagem escrita e seu emprego são assimilados pela criança consciente e voluntariamente, diferenciando-se da utilização e assimilação inconsciente do aspecto sonoro da linguagem. A linguagem escrita obriga a criança a atuar de um modo mais intelectual. Obriga-lhe a tomar consciência do próprio processo da fala.

O aprendizado da notação musical tende a obrigar o indivíduo a tomar consciência dos elementos da música, a entendê-los do ponto de vista do processo, e não de um produto acabado. Por exemplo: uma música pode ser aprendida ao violão sem a mediação da notação, mas quando a estudamos por meio da partitura podemos observar claramente o movimento das vozes interiores aos acordes, suas formas de encaminhamento e resolução das cadências, proporcionando uma relação mais consciente entre o indivíduo e essa música. É nesse sentido que se pode dizer que se trata de um entendimento processual: uma relação consciente com os elementos que sintetizam os processos de desenvolvimento da cultura musical.

Esse entendimento processual nada mais é do que a incorporação à prática individual do desenvolvimento da humanidade, a apropriação da riqueza que emana da trajetória histórica do ser humano e sua expressão musical, a transformação da atividade humana acumulada externamente nos produtos musicais escritos em elementos vivos da prática social. Assim, o aprendizado e o domínio da escrita e da leitura da música representam muito mais do que a utilização da partitura: correspondem a um salto qualitativo nas relações entre o indivíduo e a música, diretamente ligado à consciência musical.

\section{CONCLUSÃO}

A análise apresentada neste artigo aponta para uma perspectiva de defesa da riqueza da aprendizagem da notação musical. Por meio dela, a notação deixa de ser observada como um conteúdo escolar morto e mecânico, passando a ser compreendida em sua toda a sua riqueza, a qual deriva de sua importância para o desenvolvimento da prática musical. Como vimos, a trajetória da notação musical está intimamente relacionada com o desenvolvimento da própria música ocidental, e vice-versa. Isso porque ela sistematiza e torna objetivos seus elementos estruturais, fornecendo, assim, uma nova base para toda a prática musical, mesmo aquelas mais espontaneamente realizadas no cotidiano. Esse processo histórico pode ser entendido como um desenvolvimento da consciência humana sobre os aspectos da sua prática musical, algo que influencia essa própria prática, transformando as suas formas de expressão.

Partindo desse ponto de vista, percebemos que o processo de apropriação da cultura letrada da música não significa somente a aquisição da capacidade instrumental de escrita e leitura, mas também a reprodução, na consciência do indivíduo, desses elementos estruturais da prática musical. Não ensinamos a notação musical somente para ler ou escrever uma partitura, mas sim porque nela está sintetizada toda a estrutura da música ocidental 
e, assim, seu aprendizado promove uma relação mais consciente com essa estrutura. Significa promover um salto qualitativo na relação entre o indivíduo e a música, uma transformação na maneira como ele se relaciona com a sua prática musical. Ora, se a atividade educativa pode ser entendida como uma mediação entre o indivíduo e a humanidade e, consequentemente, se as formas sistematizadas de educação musical devem definir os conteúdos necessários para essa mediação, temos aqui uma fundamentação histórica e concreta para refletir sobre a importância da notação musical como conteúdo escolar.

\section{REFERENCIAS}

BENT, Ian D.; HUGHES, David W.; PROVINE, Robert C.; RASTALL, Richard; KILMER, Anne; HILEY, David; SZENDREI, Janka; PAYNE, Thomas B.; BENT, Margaret; CHEW, Geoffrey. Notation. In: GROVE MUSIC ONLINE. Oxford: Oxford University Press, 2001. Disponivel em: http://www. oxfordmusiconline.com/subscriber/article/grove/music/20114. Acesso em: 10 maio 2019.

DUARTE, Newton. A individualidade para si: contribuição a uma teoria histórico-social da formação do indivíduo. 3. ed. rev. Campinas: Autores Associados, 2013.

- Os conteúdos escolares e a ressureição dos mortos: contribuição à teoria histórico-crítica do currículo. Campinas: Autores Associados, 2016.

GROUT, Donald J.; PALISCA, Claude V. História da música ocidental. Lisboa: Gradiva, 1994.

LUKÁCS, György. Estética: la peculiaridad de lo estético. Cuestiones preliminares y de principio. Traducción: Manuel Sacritán. Barcelona: Grijalbo, 1966. v. 1.

MARX, Karl. Manuscritos econômico-filosóficos. Tradução: Jesus Ranieri. São Paulo: Boitempo, 2004.

Contribuição à crítica da economia politica. Tradução: Florestan Fernandes. 2. ed. São Paulo: Expressão Popular, 2008.

PAYNTER, John. Music in the school curriculum: why bother?. British Journal of Music Education, Cambridge, v. 19, n. 3, p. 215-226, Nov. 2002.

PENNA, Maura. Ensino da música: para além das fronteiras do conservatório. In: PEREGRINO, Yara (coord.). Da camiseta ao museu: o ensino das artes na democratização da cultura. João Pessoa: Editora Universitária, 1995. p. 129-140. 
SAVIANI, Dermeval. Escola e democracia. Edição comemorativa. Campinas: Autores Associados, 2008a.

Pedagogia histórico-crítica: primeiras aproximações. 10. ed.

Campinas: Autores Associados, 2008b.

SCHAFER, R. Murray. O ouvido pensante. Tradução: Marisa Trench de Oliveira Fonterrada. São Paulo: Editora Unesp, 1991.

TREITLER, Leo. Reading and singing: on the genesis of occidental musicwriting. Early Music History, Cambridge, v. 4, p. 135-208, 1984.

VAN WAESBERGHE, Jos Smits. The musical notation of Guido of Arezzo. Musica Disciplina, Rome, v. 5, p. 15-53, 1951.

VYGOTSKI, Lev S. Obras escogidas. Madrid: Visor, 1993. t. 2. 
Thiago Xavier de Abreu é professor do Departamento de Artes da Universidade Estadual de Ponta Grossa (UEPG), no curso de Licenciatura em Música. Graduado em Música pela Universidade Estadual de Campinas (Unicamp). Mestre em Música pelo Instituto de Artes da Universidade Estadual Paulista (Unesp). Doutor em Educação Escolar pela Faculdade de Ciências e Letras, Unesp, campus Araraquara. https://orcid.org/0000-0002-9420-9512

Newton Duarte é professor titular do Departamento de Psicologia da Educação, Faculdade de Ciências e Letras, Universidade Estadual Paulista (Unesp), campus Araraquara. Doutor em Educação pela Universidade Estadual de Campinas (Unicamp). Pós-doutorado pelo Instituto de Estudos Educacionais da Universidade de Toronto, Canadá e pelo Centro de Estudos do Pensamento Político e Social da Universidade de Sussex, Brighton, Inglaterra. Pesquisador associado ao Instituto para as Humanidades da Universidade Simon Fraser, Vancouver, Canadá. https://orcid.org/0000-0003-1837-8004 